\title{
Interstitial cystitis: The great imposter! Epidemiology, etiology, diagnosis and management
}

\author{
Jack Barkin MD FRCS FACS FICS DABU
}

J Barkin. Interstitial cystitis: The great imposter! Epidemiology, etiology, diagnosis and management. J Sex Reprod Med 2003;3(2):57-64.

\begin{abstract}
About 115 years ago, the first diagnosis of interstitial cystitis (IC) was offered as a reason to explain the pain related to scarring and inflammation in the bladder. Later, Hunner described the pathognomonic ulcer that bears his name, which is only found in about $5 \%$ to $10 \%$ of patients with IC. Today, IC is considered a controversial diagnosis. There are still a significant number of clinicians that do not believe in the diagnosis. Some people consider it to be only a diagnosis of exclusion - after every other bladder condition has been ruled out. However, population studies have demonstrated that there is a huge number of patients (mainly female) that fulfill the NIH and/or other diagnostic criteria and deserve the treatment for IC. Frequency, urgency and pain (pelvic and/or voiding) with negative urinary cultures should be considered IC and treated as such. Dyspareunia is one of the commonest complaints of the IC sufferer. The physical, sexual and emotional impact of delayed or misdiagnois of this condition can be devastating or even suicide-provoking in some patients. We now have some excellent, effective and safe intravesical and oral therapies that can provide major relief to a significant number of patients.
\end{abstract}

Key Words: Dyspareunia; Dysuria; Interstitial cystitis; Intravesical therapy; Pentosan; Polysulphate sodium

\author{
La cystite interstitielle : la grande imposteur! \\ Épidémiologie, étiologie, diagnostic et \\ traitement.
}

Il y a environ 115 ans, on a posé le premier diagnostic de cystite interstitielle $(\mathrm{CI})$ comme raison pour expliquer la douleur liée à la cicatrisation et à l'inflammation dans la vessie. Plus tard, Hunner a décrit l'ulcère pathognomonique qui porte son nom : il se manifeste seulement chez environ $5 \%$ à $10 \%$ des patients souffrant de CI. Aujourd'hui, le diagnostic de la CI est controversé. D'ailleurs, il reste encore de nombreux cliniciens qui ne croient pas à ce diagnostic. Pour certains, il s'agit seulement d'un diagnostic d'exclusion - soit après qu'on a éliminé toutes les autres conditions pouvant affecter la vessie. Cependant, des études sur la population ont démontré qu'un nombre très élevé de patients (principalement des femmes) répondent aux critères du NIH et/ou à d'autres critères de diagnostic et méritent de recevoir le traitement contre la CI. La fréquence des épisodes, l'urgence et la douleur (pelvienne et/ou lors de l'élimination) accompagnées de cultures urinaires négatives devraient être associées à la $\mathrm{CI}$ et traitées en conséquence. La dyspareunie est l'une des plaintes les plus fréquentes émanant des personnes souffrant d'une CI. Les répercussions physiques, sexuelles et émotionnelles d'un diagnostic retardé ou d'un mauvais diagnostic de cette condition peuvent être dévastatrices entraînant même le suicide chez certains patients. Il existe maintenant des traitements intravésicaux et oraux qui peuvent procurer un soulagement majeur à un nombre important de patients.

$\mathrm{V}$ aginismus, vaginitis, vestibulitis, chronic pelvic pain syndrome, pelvic floor dysfunction, recurrent urinary tract infection (UTI), trigonitis, posterior urethral syndrome, prostatodynia and chronic nonbacterial prostatitis are all conditions that have a presentation of frequency, urgency, pain and negative urine cultures, similar to those presenting symptoms of interstitial cystitis (IC). IC is sometimes difficult to diagnose because there are no true pathognomic signs of the condition that are easily elicited and reproduced. The other major concern is the reluctance of the physician to label a patient with IC. Once the patient is labelled, he or she is condemned to a life of suffering with a chronic disease that will require constant management, support and medical therapy, with a low potential for complete cure.

The impact of IC on female sexual function is significant. One of the most common complaints is dyspareunia (painful intercourse). Together with the persistent urge to void, especially with tactile stimulation or provocation with intercourse, women often avoid sex. IC should be considered in patients with dyspareunia.

There are therapies that can provide the patient with an improved quality of life if the diagnosis is made early and treated appropriately.

\section{EPIDEMIOLOGY AND HISTORY}

One of the first descriptions of IC was published in 1878, when Skene suggested that chronic inflammation and scarring in the bladder resulted in pain and frequency. It was not until 1915 that Hunner (1) described the famous 'noninfectious bladder ulcer' that bears his name.

Hunner described a red bleeding patch on the bladder walls of eight women who were experiencing urgency, frequency and pain. In 1949, Hand (2) described the discovery of "small, discrete, dot-like bleeding points" found in the bladders of 223 women with symptoms after they had their second bladder distension. In 1978, Walsh coined the term 'glomerulations' to describe that phenomenon.

In the same year, Messing and Stamey (3) published the first landmark paper describing the current understanding of this sometimes described 'disease of exclusion', and pleading

Department of Urology, Humber River Regional Hospital and The Female/Male Health Centre, Toronto, Ontario

Correspondence and reprints: Dr Jack Barkin, 960 Lawrence Avenue West, Suite 404, Toronto, Ontario M6A 3 B5.

Telephone 416-256-2737, fax 416-256-9098, e-mail j.barkin@rogers.com 
TABLE 1

National Institutes of Health diagnostic criteria for interstitial cystitis

\begin{tabular}{ll}
\hline Category & Inclusion \\
\hline A & At least one of the following: \\
& - Diffuse glomerulations (greater than 10) in at least three \\
& quadrants \\
& - A classic Hunner's ulcer \\
B & At least one of the following: \\
& - Bladder pain \\
& Urinary urgency \\
\hline
\end{tabular}

for early diagnosis to obviate a better cure rate. They defined a patient with IC as having painful bladder symptoms, no infection and the presence of glomerulations after hydrostatic distension of the bladder.

In 1984, New York orthopedic surgeon Vicki Ratner, who suffered from the disease, founded The Interstitial Cystitis Association. Her persistent and persuasive work stimulated the National Institutes of Health (NIH) to convene workshops in 1987 and 1988 to develop consensus opinions regarding the diagnosis of the disease (4). The suggestions for diagnosis were to be used in clinical trials only. These criteria seem too restrictive for clinical practice and, as shown in Table 1, would eliminate many patients who appear to have IC. Because it was felt that those with the NIH criteria were only a subset of patients with IC, the IC Data Base (ICDB) was established to identify the disease in the population and to evaluate its progression over time (5).

The exclusions also made it difficult to include all sufferers, such as the following:

- Age less than 18 years

- Frequency while awake less than eight times

- Nocturia less than two times

- Maximum bladder capacity while awake greater than $350 \mathrm{~mL}$

- No urge to void at $100 \mathrm{cc}$ gas or $150 \mathrm{~mL}$ water

- Involuntary bladder contractions on cystometrogram

- Symptoms lasting less than nine months

- Symptoms relieved by antimicrobials or anticholinergics

- Urinary tract or prostatic infections in last three months

- Active genital herpes or vaginitis

- Urethral diverticulum

- Uterine, cervical, vaginal or urethral cancer in last five years

- History of cyclophosphamide, chemical, tuberculosis or radiation cystitis

- History of bladder tumours (benign or malignant)

There have been a few population-based studies but, unfortunately, the inclusion criteria were different. The first study,
TABLE 2

Causative theories of interstitial cystitis

- Toxic substances in urine

- Infection

- Psychogenic factors

- Immune disorder (allergy)

- Neurogenic causes

- Dysfunctional or 'leaky' epithelium

- Visceral pain syndrome

- Possibly also hormonal or genetic factors, or food intolerance

by Oravisto (6), reviewed the IC population in a region of Finland. He found the prevalence rate to be 10.1 patients per 100,000 population. In the United States, a population-based Nurses Health Study (7) established a prevalence of between 52 to 67 patients per 100,000 .

The estimate today is that there are currently between 0.5 and 1 million sufferers in the United States and a proportionate number in Canada (8). Approximately 5000 Canadians and between 20,000 to 60,000 Americans are diagnosed each year (9)

\section{ETIOLOGY AND PATHOGENESIS}

Since Hunner first suggested that the 'elusive ulcer' resulted from chronic bacterial infection (1), there have been numerous theories regarding the etiology of IC (Table 2).

The exact etiology of IC has not been established. It has been suggested, therefore, that IC is multifactorial, both in causation and pathogenesis $(10,11)$.

\section{Infection}

No specific bacterial or viral agent has ever been associated with IC. There have been at least 26 different studies investigating possible links between IC and aerobic bacteria, anerobic bacteria, fungus, mycoplasma, etc, all of which were inconclusive. Response to antibiotic therapy is variable. Many patients report a history of UTI but, by definition, the urine must be sterile to make the diagnosis of IC. Warren (12) has suggested that infection and other mechanisms may lead to bladder injury and an autoimmune response.

Another hypothesis is that the patients have 'low count bacteriuria' (13) or bacteria that is adherent to or embedded in the bladder wall (14) that can only be elucidated by special techniques. It is now possible to identify the DNA of bacteria using the polymerase chain reaction. Domingue et al (15) have isolated these bacteria in IC patients with sterile urine, but the significance of this was uncertain because the majority of patients did not respond to antibiotics.

\section{Psychogenic factors}

This issue brings forth the age old question about 'the chicken or the egg'. Moderate to severe IC can produce a wide spectrum of psychosocial manifestations including depression, feelings of hopelessness, low self esteem and even feelings of suicide (16). IC patients require careful consideration and assessment. It can take four to five years and visits to numerous physicians before the typical IC patient is diagnosed and treated (17) 


\section{Immunologic}

There is often a coexistence and similarity in presentation to certain disorders such as lupus (18) or inflammatory bowel disorders. There is a higher rate of IC in both of these populations compared with the general population (19). The diseases are more prominent in women, show noninfectious inflammatory changes and can coexist with allergic disorders.

However, the numerous studies examining serology, cell typing or atopy have not demonstrated an autoimmune disorder (13). There does appear to be an association between mast cells and IC in some patients. Mast cells seem to be more prominent in the ulcerative versus the glomerular type of IC. Mast cells are key elements in immunoglobulin E-mediated immediate hypersensitivity (20). However, no studies have demonstrated a hypersensitivity reaction in IC. The effects of mast cell response can lead to a proposed neuroinflammatory etiology for the disease or can be one of the exacerbators of the disease (21). They can stimulate the submucosal response as seen in the 'leaky mucosal' theory.

\section{Leaky urothelium}

In 1983, Parsons et al (22) first proposed what has become the most accepted theory concerning the etiology and pathogenesis of IC. The inner wall of the bladder or the mucosal layer is covered by a film of mucin composed of glycosaminoglycan (GAG). Each GAG unit consists of three molecules that are derived from glucose and chemically bonded together. Hyaluronic acid (HA), heparan sulfate, chondroitin, dermatan and keratan sulfate are the major classes of GAGs (23).

This mucin coating or GAG layer has a protective role for the bladder. It appears to prevent binding of bacteria to the wall and to defend against 'harmful urinary substances' gaining access to the submucosal layer containing the muscles and nerves (24).

There is a negatively charged oxygen atom on the GAG that binds strongly to the positively charged hydrogen atoms of water molecules. This creates a hydrophilic GAG layer that presents as a layer of water between the lumen of the bladder and the urothelium. This water layer prevents adhesion and penetration into the underlying cells of microcrystals, ions, proteins, bacteria and other irritants (9).

According to Parson, this bladder insult weakens or damages the GAG layer. This in turn allows certain solutes to reach the deeper submucosal layers and results in tissue injury that may cause mast cell release or degranulation, increased inflammatory cells, release of cytokines and sensory nerve depolarization creating the frequency, urgency, bladder pain, pelvic pain and other symptoms of IC (25).

This theory has been demonstrated by applying protamine sulfate to human and animal bladder tissue. Protamine will reverse the effect of heparan. One can measure the increased permeability to urea and calcium in these protamine-treated tissues. If one then adds heparan or pentosan polysulfate sodium, the permeability is reversed (9).

It is this leaking urothelium that sets up the cascade of events that creates the symptoms and signs of IC. The major ion that can cause damage to the underlying muscles and nerves is potassium. Potassium and other solutes then activate the nerve fibres which will potentially result in histamine release from the mast cells (26). There is activation of $\mathrm{C}$-fibres, release of substance $\mathrm{P}$ and activation of the mast cells and other substances that can increase the ease of permeability. This cyclical injury and response paradigm eventually results in an upregulation of the more central (spinal cord) nerve fibres that account for 'visceral pain syndrome' as described by Wesselmann (27).

\section{DIAGNOSIS}

IC is a common clinical problem. Patients are often labelled with other diagnoses such as recurrent cystitis. In women, the incidence of IC is $2 \%$ to $4 \%$ but only about $20 \%$ of those patients will have a clinically significant course that interferes with their activities of daily life (28).

The key to diagnosis is to remember that the criteria set out in the NIH and National Institute of Arthritis, Diabetes, Digestive and Kidney Diseases (NIDDK) guidelines for the diagnosis of IC are just that. If physicians wait for all of those criteria to be met, then the patient will already be suffering from a severe, even debilitating form of the disease.

IC should not be reserved as a diagnosis of exclusion. Instead, frequency, urgency, pain and negative urinary cultures should be considered IC until proven otherwise.

The patient who complains of an 'infection' every time she has intercourse, even if the cultures are negative, may not have 'honeymoon cystitis', but possibly early IC. In the early stages, the symptoms can mimic endometriosis, recurrent UTI, posterior urethral syndrome or chronic pelvic pain syndrome. If not treated promptly, it may progress. If treated early and appropriately, progression may be prevented.

More women than men are affected with IC, with a ratio of $9: 1$. The median age at diagnosis is between 42 and 46 years, but almost $25 \%$ of patients will develop symptoms before the age of 30 (14).

\section{Symptoms and signs}

Symptoms of IC include the following:

- Urgency

- Frequency

- Pain in pelvis, bladder, perineal area, thighs, prostate or urethra

\section{- Dyspareunia}

- Flares and remissions associated with sexual intercourse, diet, travel, stress and premenstruation

- Negative urinary cultures

\section{Physical examination}

Female patients should be examined for the presence of anterior vaginal wall tenderness, suprapubic tenderness or pelvic floor spasm. Male patients should be checked for the presence of sphincter spasm, tender rectal area, or pain radiating to the testes or penis.

\section{Conditions to rule out}

Vaginitis, urethral diverticulum, vulvodynia, uterovaginal prolapse, pelvic floor dysfunction, endometriosis and bladder cancer should be ruled out before making a diagnosis of IC.

\section{Concomitant diseases}

Concomitant diseases may include gynecological conditions, irritable bowel syndrome, sinusitis, drug hypersensitivity, fibromyalgia and migraine headaches. 


\section{DIAGNOSTIC TOOLS}

Diagnostic tools for IC are as follows:

- Urine: urinalysis, culture, cytology, antiproliferative factor (APF)

- Voiding $\log$

- O'Leary-Sant IC symptom and problem indexes

- Potassium sensitivity test

- Urodynamics

- Cystoscopy, hydrodistension or biopsy

\section{Voiding log}

The voiding log is a simple and useful tool. It provides a basis for the diagnosis of IC and a measurement of the response to therapy. Voided volume and frequency in the IC patient (average 16.5 voids per day) differs from that of the normal population (average 6.5 voids per day) (29). In IC patients, average bladder capacity is $110 \mathrm{~mL}$ and over $95 \%$ of such patients experience increased sensory urgency at less than $100 \mathrm{~mL}$ (30). It is important to establish a baseline number in order to counsel and encourage the patient during therapy. The patient maintains the log for $48 \mathrm{~h}$ and records intake and output.

\section{O'Leary-Sant problem indexes}

These symptom scores have been used in clinical trials and patient management for many years and have been applied to cardiac problems, benign prostatic hypertrophy, prostatitis and IC (31).

The IC symptom index and problem index were developed to capture the most significant pain and voiding complaints of the IC patient and determine the relative impact. By quantifying the results, one is able to establish a baseline comparison to assess response to therapy. Both of the questionnaires were designed for self-administration, to mitigate the need for an interviewer (32). They are complementary and important because it is often the problem index that dictates the desire for treatment and the escalation of treatment modalities, not the presence of the symptoms themselves (33).

The indexes are useful in the evaluation of the patient and can be used to discriminate between normal and IC patients. In a study by Wasson et al (33), almost all patients with IC had a score greater than six, while the controls had a score of less than six. The indexes are simple to administer and the patient acts as his own control. They have been validated and are reproducible.

\section{Potassium sensitivity test}

Parsons, who first promoted the concept of epithelial permeability, devised a simple test to assess the integrity of the GAG layer in patients. As previously discussed, IC patients tend toward mucosal leaking which allows urinary solutes such as potassium to reach the submucosal layer where it can irritate the sensory nerves and muscles, thereby causing pain and urgency.

The practice is to first introduce $50 \mathrm{~mL}$ of water into the patient's bladder. The response of pain and urgency is measured on a scale from one to five, with five being the worst. This is followed by an instillation of a potassium chloride solution prepared by adding $40 \mathrm{mEq}$ potassium chloride to $100 \mathrm{~mL}$ of sterile water and introducing $45 \mathrm{~mL}$ of this solution into the bladder.

If the patient does not respond to the water but reports an increase in pain or urgency of two or more on the scale when given the potassium chloride solution, the test result is considered to be positive. The test is positive in $70 \%$ to $90 \%$ of IC patients (34).

A positive test is an indicator of possible IC, but the converse is not true. The results of over 1100 potassium sensitivity tests have been published and the numbers demonstrate that over $80 \%$ of patients with IC have a positive test. False negatives can occur if the patient has had a recent treatment with heparin, dimethylsulfoxide (DMSO), high doses of pain medications, a recent hydrodistension or is so maximally stimulated with pain already that there is no room for an increased response. Also, due to the intermittent nature of the disease, the patient with IC may test negative on any given day.

\section{Urodynamics}

Urodynamics are usually unnecessary unless there is concern that the patient has a neurogenic bladder. This is unusual, especially in the younger or middle aged patient. There can be some confusion with the 'overactive bladder' diagnosis, but in that situation there is usually no pain and no response to potassium chloride (35).

\section{Cytoscopy and hydrodistension}

Studies have shown that hydrodistension can increase the bladder capacity of patients and provide some symptomatic relief, but for a short time only. Under anesthesia, the IC patient has a much lower bladder capacity compared with the normal patient ( $575 \mathrm{~mL}$ versus $1115 \mathrm{~mL}$ ) (36).

If a Hunner's ulcer is found, the patient is usually suffering from more severe symptoms and will have a smaller bladder capacity. Glomerulations may be seen, but again, the absence of glomerulations does not preclude the diagnosis of IC if the symptoms and history are significant. In a major study of the ICDB, $75 \%$ of the patients had bloody effluent and over $91 \%$ had at least some glomerulations. This did not correlate with the degree of symptoms (37).

Cystoscopy can be helpful to rule out bladder cancer and to demonstrate certain positive findings, but a negative cystoscopy should not rule out IC.

An assessment of 379 women who met the criteria to be included in the ICDB was recently performed. One hundred forty-eight of the patients had cystoscopy and hydrodistension. Almost $90 \%$ of the patients that met the NIDDK criteria were diagnosed by experienced clinicians to have clinical IC. However, if the strict NIDDK criteria were used, including cystoscopy, more than $60 \%$ of the patients that clinicians considered 'definitely or likely' to have IC would have been misdiagnosed (8).

\section{APF}

This is mainly an investigative tool. This low molecular weight protein is found in higher concentrations in IC patients than in the normal population. Its function is to inhibit bladder epithelial proliferation. The mechanism is complex. It seems that APF decreases heparin-binding epidermal growth factor. This is one of the components necessary for the integrity of the GAG layer. In one study (38), the finding of increased APF was $94 \%$ sensitive and $95 \%$ specific for IC. 


\section{Glycoprotein 51}

Glycoprotein (GP) 51 is produced throughout the urinary tract. The bladder is the prime source of GP51. It is produced and secreted by the transitional epithelium. Researchers at Thomas Jefferson University in Pennsylvania (39) determined that low levels of GP51 are specific to patients with IC. They have lower levels of GP51 than patients with any other urinary disease.

\section{Nitric oxide}

Nitric oxide (NO) is produced in the mucosal layers of the hollow viscus organs in the body. $\mathrm{NO}$ can also be found in the corpora cavernosal blood vessels of the penis. The concentration of $\mathrm{NO}$ in the bloodstream has been found to increase in patients who are suffering from inflammatory conditions of organs that contain hollow areas, such as in ulcerative colitis or in the bronchial airways of patients with chronic bronchitis or asthma. In these cases, the disease is also assumed to be caused by an inflammatory process. In certain studies, the investigators have found significantly higher concentrations of $\mathrm{NO}$ in IC patients than in the normal controls (an 18-fold increase) (40). The same authors have suggested that, in high concentrations, $\mathrm{NO}$ can increase the production of free radicals. These free radicals can also damage the mucosal lining of the bladder.

\section{CHRONIC PELVIC PAIN SYNDROME: SIMILARITY TO IC}

Chronic nonbacterial prostatitis has recently been reclassified as chronic pelvic pain syndrome (CPPS), categories IIIA (inflammatory cells) or IIIB (no white blood cells).

The symptoms and signs of CPPS are pain, urgency, frequency and negative cultures which, as previously outlined, are very similar to the symptoms of IC in women. CPPS does not routinely respond to antibiotics, anti-inflammatories or other conservative measures.

A Canadian study (41) was undertaken to assess whether treatment with pentosan polysulfate (PPS) $100 \mathrm{mg}$ TID for six months would improve baseline scores in a symptom severity index, a symptom frequency questionnaire, the NIH Chronic Prostatitis Symptom Pain Index, a quality of life assessment and a global assessment questionnaire.

Twenty-eight patients with symptom durations between nine and 12 years were evaluated. There were dramatic improvements in all indexes and, at six months, the global assessment questionnaire saw mild, moderate and marked improvement in 33\%,19\% and 15\% of patients, respectively. This would suggest that CPPS in men can be addressed by treating it in the same manner as treatment of IC in women. Again, physicians have been reluctant to use the label of IC in men and many would rather use the term chronic prostatitis (41).

\section{TREATMENT}

The treatment of IC is a function of the time of diagnosis, duration, multiplicity and severity of symptoms. The key is to recognize it early so that the symptoms are not excessive and the bladder damage is not too significant. Depending where in the injury cycle the patient is situated, treatment is modified to correct for that problem.

The principles of IC therapy are directed at the three areas of major pathology:
- Epithelial and mucosal dysfunction

- Modulation of neural activity

- Stabilization of mast cells

Treatment may involve one or a combination of lifestyle measures, oral medication and other approaches including, on rare occasions, surgery.

\section{LIFESTYLE}

In general, tea, coffee, alcohol, spicy foods, smoking, stress, travel, high potassium foods and lack of rest can aggravate IC. The patient must be his or her own monitor. If a certain food or activity causes a flare, then that instigating factor should be avoided.

\section{ORAL MEDICATION}

\section{PPS}

PPS is the only approved oral medication for the treatment of IC. There have been at least five double-blind, placebocontrolled studies, all of which have demonstrated that $100 \mathrm{mg}$ TID of PPS provides significant pain relief over placebo $(42-46)$

The mechanism of activity of PPS is still unknown. PPS is a plant-derived, semisynthetic mucopolysaccharide. It is chemically and structurally similar to the GAGs that occur naturally in, and form the protective layer for, the bladder. In preliminary clinical models, PPS adhered to the mucosal layer of the bladder. It may be involved in rebuilding the damaged bladder wall and may act as a buffer to prevent permeability. This may prevent the inflammatory response. At the 2001 American Urological Association meeting, Tchetgen suggested that PPS may work by selective inhibition of potential inducers of inflammation. She explained that PPS may actually bind to the toxins in urine itself, which could account for the variable clinical response.

Knowing that PPS is effective in the management of the pain and bladder discomfort of IC, investigators questioned whether a higher than standard dose would be safe and provide for a more rapid response in the relief of symptoms without additional side effects. The PPS dose-escalation, double-blind study (47) evaluated over 200 patients who were given daily doses of $300 \mathrm{mg}, 600 \mathrm{mg}$ or $900 \mathrm{mg}$ PPS for eight months. The results were significant and are listed as follows:

- Improvement in the IC symptom score occurred as early as four weeks into treatment.

- There was no significant difference in the side effect profile regardless of dosage, except for the incidence of diarrhea.

- At the end of the trial, almost $80 \%$ of patients had achieved a significant response. However, the response curve had not yet plateaued. This emphasizes the need for patients to remain on PPS for as long as possible. They should not be discouraged if there is no response for up to six months. Once a response commences, the maximum response will be obtained beyond eight months. The duration of therapy is more important than the dose. 


\section{Antihistamines}

If there is significant atopy or an allergic history in the individual or if the flares seem to be worse in the allergy season, the use of antihistamines may be appropriate. They can inhibit mast cell release and decrease the allergic response in the patient. This may also diminish inflammation in the wall of the bladder. Finally, antihistamines may have a sedative effect and promote fuller sleep.

Hydroxyzine hydrochloride at a dose of $25 \mathrm{mg}$ nightly for one week, with escalation up to $75 \mathrm{mg}$ nightly, may be appropriate. Treatment may take up to three months before positive effect is perceived. One open-label study on 140 patients that responded to a visual analog symptom scale reported a $40 \%$ reduction in symptom scores after three months. In those patients with a history of allergies, mean improvement was $55 \%$. The main side effect was early morning sedation, which lasted one to five days. The benefits were decreased nocturia and frequency with an associated increase in sleep (48).

\section{Antidepressants}

Two different families of antidepressants have been used. There are some similarities in the effects between the tricyclic antidepressants and the selective serotonin reuptake inhibitors. Both have some antihistaminic activity. Both have sedative effects that may help the patient to sleep.

The tricyclics block the reuptake of serotonin and epinephrine, and possess central and peripheral anticholinergic effects. The most commonly prescribed tricyclic is amitryptyline (49) at a dose of between 25 and $75 \mathrm{mg}$ daily. Side effects include fatigue, dry mouth and constipation.

The selective serotonin reuptake inhibitors also have some anticholinergic actions in addition to preventing serotonin reuptake, may decrease pain and can also help with sleep.

Paroxetine or fluoxetine (each at 10 to $40 \mathrm{mg}$ OD) may also be beneficial as an alternative. There have been no controlled, blinded studies on either family of drugs.

\section{Anticholinergics}

Anticholinergic drugs may be helpful to reduce frequent urination. Pain control is essential before anticholinergic therapy.

Imipramine, oxybutynin, tolterodine, oxybutynin XL, flavoxate or dicyclomine in whatever dosages necessary and not mitigated by the side effects, are appropriate as single agents or in combination.

\section{Neuroleptics}

It has been postulated that there is an upregulation of the sensory nerve fibres in IC. There are drugs that may 'down-regulate' the overstimulated nerve fibres.

Gabapentin, phenytoin and carbamazepine have all been used in this situation and are usually added in very severe cases. High doses must be used, for example, up to $3200 \mathrm{mg}$ daily of gabapentin on a daily basis. These drugs may decrease pain and frequency.

\section{Analgesics (systemic or urinary)}

It is critical to attempt to relieve the pain in IC. It is the pain and urgency that prevents working and interferes with quality of life.

Combinations of anti-inflammatory agents, such as celecoxib, indomethacin, rofecoxib or naproxen, are sometimes coupled with the narcotics. For flares or chronic IC, urinary analgesics such as phenazopyridine may be helpful.

Narcotics should only be used in the severe acute situations and tapered as soon as possible.

These strong analgesics are sometimes used in combination with the skeletal muscle relaxants like diazepam or baclofen.

DMSO

\section{INTRAVESICAL AGENTS}

DMSO was first approved by the USA Food and Drug Administration in 1978 to treat IC. It is reported to have antiinflammatory, analgesic and muscle relaxant properties when applied to the bladder. It has also been shown to dissolve collagen and enhance drug penetration (50).

DMSO has been used extensively in treatment of IC. The response rates vary from $50 \%$ to $90 \%$ with about a $35 \%$ to $40 \%$ relapse rate. A second course of therapy will salvage about $50 \%$ of those that relapse.

Treatment involves weekly bladder instillations of $50 \mathrm{~mL}$ of $50 \%$ DMSO. These remain in the bladder for 15 to $30 \mathrm{~min}$. Patients may experience some increased bladder irritability initially, as well as chemical cystitis or 'garlic-like' breath odour because of the pulmonary excreton of the DMSO as dimethyl sulfide.

Occasionally, DMSO may be given in combination with 10,000 units of heparin to achieve a longer lasting response (51).

\section{Heparin}

Heparin has the ability to recoat or replace the GAG layer in some patients. There are some individuals who will use heparin alone (employing self-catheterization) on a daily basis to treat IC. Such patients use 40,000 to 50,000 units in 10 to $15 \mathrm{~mL}$ saline on a daily basis. It usually takes up to four months for a response. It may be used intermittently for the treatment of flares.

\section{HA}

HA is a GAG present in all connective tissues. It is also present in the GAG layer of the bladder. The hypothesis is that HA could be used to treat IC by repairing the GAG layer. A study was completed using $40 \mathrm{mg}$ of HA dissolved to a volume of $50 \mathrm{~mL}$ normal saline and instilled weekly for four weeks and then monthly for up to one year. There was up to $71 \%$ (complete and partial) response by week 12 , but after week 24 there was a decrease in the effectiveness of the medication (52).

\section{Other intravesical agents}

Sodium oxychlorosene, silver nitrate and, more recently, bacillus of Calmette-Guérin have been employed. The rationale is that if one can cause a significant inflammatory reaction (either chemical or immunological), this will cause a denuding of the bladder with a secondary spontaneous reparative effect. This repair will rebuild the GAG layer and may correct the leak. Some studies on bacillus of Calmette-Guérin have provided a reasonable symptom response after six weeks without significant side effects (53).

\section{BLADDER HYDRODISTENSION}

Bladder hydrodistension is performed under general anesthesia. The bladder is distended using water pressure to a level of $100 \mathrm{~cm}$. The bladder remains full for $2 \mathrm{~min}$ and is then emptied. At that time, one can sometimes see the Hunner's ulcer, 
glomerulations or a bloody effluent, all of which would suggest IC. Occasionally, a biopsy is performed at that time to look for inflammation and mast cells.

The process can sometimes temporarily relieve the symptoms of urgency and frequency in up to $60 \%$ of patients (9). The response can last up to about six months. The distension may break down the fibrosis and cause some ischemia to the nerve fibres which will increase bladder capacity and decrease the urgency. The significant hypotonic effect of the water may cause rupture of the mast cells and degranulation, which can initially exacerbate the symptoms but may later cause alleviation because of the loss of the histaminic effect (54).

\section{NERVE STIMULATION}

The upregulation of the sacral nerve fibres is the reason why the pain may be felt away from the bladder. If one can stimulate the sacral nerves, there could be resolution of the pain and frequency. Temporary sacral nerve stimulators can be implanted and tested. In one study by Caraballo et al (55), 16 of 17 patients considered the procedure to be a success and would have it done again. In the very severe patients who responded, a permanent sacral nerve stimulator may be implanted.

\section{OTHER TECHNIQUES}

Biofeedback and pelvic floor massages have been studied. They have had limited success in decreasing the frequency and

\section{REFERENCES}

1. Hunner GA. Rare type of bladder ulcer in women: Report of cases. Boston Med Soc J 1915;172:660.

2. Hand JR. Interstitial cystitis: Report of 223 cases (204 women and 19 men). J Urol 1949;61:291-310.

3. Messing EM, Stamey TA. Interstitial cystitis: Early diagnosis, pathology and treatment. Urology 1978;12:381-92.

4. Gillenwater JY, Wein AJ. Summary of the National Institute of arthritis, Diabetes, Digestive and Kidney diseases (NIDDK) Workshop on Interstitial Cystitis, National Institutes of Health, Bethesda, Maryland. August 28-29, 1987. J Urol 1988;140:203-6.

5. Hanno P, Levin RM, Monson FC, et al. Diagnosis of interstitial cystitis. J Urol 1990;143:278-81.

6. Oravisto KJ. Epidemiology of interstitial cystitis. Ann Chir Gynaecol Fenn 1975;64:75-7.

7. Curhan GC, Speizer FP, Hunter DJ, Curhan SG, Stampfer MJ. Epidemiology of interstitial cystitis: a population based study. J Urol $1999 ; 161: 549-52$.

8. Hanno PM, Landis JR, Mathews-Cook Y, Kusek J, Nyberg L Jr. The diagnosis of interstitial cystitis revisited: Lessons learned from the National Institutes of Health interstitial cystitis database study. J Urol 1999;161:553-7.

9. Parsons CL, Parsons JK. Interstitial cystitis. In: Raz S, Valkoff S, eds. Female Urology, 2nd edition. Philadelphia: WB Saunders, 1996:167-82.

10. Sant GR. Interstitial cystitis: Pathophysiology, clinical evaluation and treatment. In: Urology Annual, Volume 3. Norwalk: Appleton \& Lange, 1989:171-96

11. Holm-Bentzen M. Etiology: Etiologic and pathogenetic theories in Interstitial Cystitis. In: Hanno P, Staskin D, eds. Interstitial Cystitis. London: Springer-Verlag, 1990:63-77.

12. Warren JW. Interstitial cystitis as an infectious disease. Urol Clin North Am 1994;21:31-9.

13. Ratliff TL, Klutke CG, McDougall EM. The etiology of interstitial cystitis. Urol Clin North Am 1994;21:21-30.

14. Elbadawi A. Interstitial cystitis: A critique of current concepts with a new proposal for pathologic diagnosis and pathogenesis. Urology 1997;49(Suppl 5a):14-34.

15. Domingue GJ, Ghoniem GM, Bost KL, Fermin C, Human LG. Dormant microbes in interstitial cystitis. J Urol 1995;153:1321-6.

16. Draucker C. Coping with a difficult-to-diagnose illness: The example of interstitial cystitis. Health Care Women Int 1991;12:191. urgency. The pelvic muscle spasm may be relieved after many months of therapy.

\section{SURGERY}

Surgery is an approach of last resort. If symptomatic response cannot be achieved with a combination of any of the other modalities, then surgery may be offered. These patients must be very debilitated with their level of discomfort. Surgery usually involves cystectomy with diversion (55). If an augmentation is performed, IC may develop in the neo bladder as well. Less than $10 \%$ of patients will require this radical approach.

\section{CONCLUSION}

IC can be easily diagnosed if one maintains a high level of suspicion. The symptom complex of pain, frequency, urgency, and negative urinary cultures and cytology is IC until proven otherwise. The complaint of painful intercourse or dyspareunia when associated with the frequency and urgency should also alert the physician to the interpersonal and marital relationships of the IC sufferer. These women and their partners are very highly motivated to correct the problem to resume enjoyable and painless sexual activity. These are among the most grateful patients. With early intervention and the use of the right medications or combinations of therapy for the proper length of time, the chances of symptom control and possibly cure are very high (56).

17. Whitmore KE. Self-care regimen for patients with interstitial cystitis. Urol Cli North Am 1994;21:121.

18. Fister GM. Similarity of interstitial cystitis (Hunners' ulcer) to lupus erythematosis. J Urol 1938;40:37-51.

19. Alagiri M, Chottiner S, Rattner V, Slade D, Hanno PM. Interstitial cystitis: Unexplained association with other chronic disease and pain syndromes. Urology 1997;49(Suppl 5a):52-7.

20. Galli SJ. New concepts about the mast cell. N Engl J Med 1993;328:257-65.

21. White MV, et al. Mast cell secretagogues: histamine-releasing factors and neuropeptides. The Mast Cell in Health and Disease. New York: Marcel Dekker, 1993:109-28.

22. Parsons CL, Schmidt JD, Pollen JJ. Successful treatment of interstitial cystitis with sodium pentosanpolysulfate. J Urol 1983;130:51-3.

23. Hurst RE, Zebrowski R. Identification of proteoglycans at high density on bovine and human bladder luminal surface. J Urol 1994;152:1641-5.

24. Parsons CL. Epithelial coating techniques in the treatment of interstitial cystitis. Urology 1997;49(suppl 5a):100-4.

25. Parsons CL. The therapeutic role sulfated polysaccharides in the urinary bladder. Urol Clin North Am 1994;21:93-9.

26. Theoharides TC, Sant GR, el Mansouri M, Letourneau R, Ucci AA Jr, Meares EM. Activation of bladder mast cells in interstitial cystitis: A light and electron microscopic study. J Urol 1995;153:629-36.

27. Wesselmann U. A call for recognizing, legitimizing and treating chronic visceral pain syndromes. J Pain 1999;8:146-50.

28. Parsons CL. Interstitial cystitis: Breaking the barriers to diagnosis and treatment. Primary Care Comm- symposium report. April 1999.

29. Parsons CL, Koprowski PF. Interstitial cystitis: Successful management by increasing urinary voiding volumes. Urology 1991;37:207-12.

30. Parsons CL, Stein PC, Bidair M, Lebow D. Abnormal sensitivity to intravesical potassium in interstitial cystitis and radiation cystitis. Neurourol Urodynam 1994;13:515-20.

31. O'Leary MP, Barry MJ, Fowler FJ Jr. Hard measures of objective outcomes: validating symptom indexes in urology. J Urol 1992;148:1546-8.

32. O'Leary MP, Sant GR, Fowler FJ Jr, Whitmore KE, Spolarich-Kroll J. The interstitial cystitis symptom index and problem index. Urology 1997;49(Suppl 5a):58-63

33. Wasson JH, Reda DJ, Bruskewitz RC, Ellinson J, Keller AM, Henderson WG. A comparison of transurethral surgery with watchful 
waiting for moderate symptoms of benign prostatic hyperplasia. N Engl J Med 1995;332:75-9.

34. Parsons CL, Greenberger M, Gabal L, Bidair M, Barme G. The role of urinary potassium in the pathogenesis and diagnosis of interstitial cystitis. J Urol 1998;159:1862-7.

35. Bernie JE, Hagey S, Albo ME, Parsons CL. The intravesical potassium sensitivity test and urodynamics: Implications in a large cohort of patients with lower urinary tract symptoms. J Urol 2001;166:158.

36. Parsons CL. Interstitial Cystitis in Urogynecology and Urodynamics: Theory and Practice. Ostegard D, ed. Philadelphia: LippincottWilliams and Wilkins, 1996:409-25.

37. Messing E, Pauk D, Schaeffer A, et al. Associations among cystoscopic findings and symptoms and physical cystitis examination findings in women enrolled in the interstitial data base study. Urology 1997;49(Suppl 5a):81-5.

38. Keay S, Warren JW, Zhang CO, Tu LM, Gordon DA, Whitmore KE. Antiproliferative activity is present in the bladder but not renal pelvic urine from interstitial cystitis patients. J Urol 1999;162:1487-9.

39. Byrne DS, Sedor JF, Estojak J, Fitzpatrick KJ, Chiura AN Mulholland SG. The urinary glycoprotein GP51 as a clinical marker for interstitial cystitis. J Urol 1999;161:1786-90.

40. Ehren I, Hosseini A, Lundberg JO, Wiklund NP. Nitric oxide: A useful gas in the detection of lower urinary tract inflammation. J Urol 1999;162:327-9.

41. Nickel JC, Barkin J. Pentosan polysulfate therapy for chronic nonbacterial prostatitis (chronic pelvic pain syndrome category 111A): A prospective multicenter clinical trial. Urology 2000;56:413-7.

42. Parsons CL, Mulholland SG. Successful therapy of interstitial cystitis with pentosanpolysulfate. J Urol 1987;138:513-6.

43. Holm-Bentzen M, Jacobsen F, Nerstrom B, et al. A prospective, double-blind, clinically-controlled multicenter trial of sodium pentosanpolysulfate in the treatment of interstitial cystitis and related painful bladder disease. J Urol 1987;138:503-7.
44. Mulholland SG, Hanno P, Parsons CL, Sant GR, Staskin DR. Pentosan polysulfate sodium for therapy of interstitial cystitis: A double-blind, placebo-controlled clinical study. Urology 1990;35:552-8.

45. Bade JJ, Laseur M, Niewenburg A, van der Weele LT, Mensink HJ. A placebo-controlled study of intravesical pentosanpolysulfate for the treatment of interstitial cystitis. Br J Urol 1997;79:168-71.

46. Hwang P, Auclair B, Beechinor D, Diment M, Einarson TR. Efficacy of pentosan polysulfate in the treatment of interstitial cystitis: A metaanalysis. Urology 1997;50:39-43.

47. Nickel JC, Forrest J, Barkin J, et al. Safety and efficacy of up to 900 $\mathrm{mg} /$ day of pentosan polysulphate sodium (Elmiron) in patients with interstitial cystitis. Urology 2001;57(Suppl 6a):122. (Abst)

48. Theoharides MD, Sant G. Hydroxyzine therapy for interstitial cystitis. Urology 1997;(Suppl 5a):108-10.

49. Hanno PM. Amitriptyline in the treatment of interstitial cystitis. Urol Clin N Am 1994;21:89-92.

50. Ruggieri MR, Chelsky MJ, Rosen SI, Shickley TJ, Hanno PM. Current findings and future research avenues in the study of interstitial cystitis. Urol Clin North Am 1994;21:163-76.

51. Perez-Marrero R, Emerson LE. Prolongation of response to DMSO by heparin maintenance. Urology 1993;41(Suppl 1):64-6.

52. Morales A, Emerson L, Nickel JC. Intravesical hyalurinic acid in the treatment of refractory interstitial cystitis. Urology 1997;49(suppl 5a):111-3.

53. Peters KM, Diokno AC, Steinert BW, Gonzalez JA. The efficacy of intravesical bacillus Calmette-guérin in the treatment of interstitial cystitis. J Urol 1998;159:1483-6.

54. Erickson DR, Simon LJ, Belchis DA. Relationships between bladder inflammation and other clinical features of interstitial cystitis. Urology 1994;44:655-9.

55. Caraballo R, Bologna RA, Lukban J, Whitmore KE. Sacral nerve stimulation as a treatment for urge incontinence and associated pelvic floor disorders at a pelvic floor centre: A follow-up study. Urology 
2001;57(Suppl 1):121.

56. Irwin PP, Galloway NT. Surgical management of interstitial cystitis. Urol Clin North Am 1994;21:145-51. 